\title{
Barriers and facilitators to e-learning in palliative care
}

Joanne Callinan, Library and Information Service, Milford Care Centre, Limerick, Republic of Ireland

joanne_callinan@hotmail.com

\section{Abstract}

Background: E-learning provides opportunities for flexible learning to those who cannot access palliative education in the traditional class, but it also presents learners with challenges. The study aims to identify the barriers and facilitators to accessing e-learning courses in palliative care.

Method Cross-sectional surveys were developed, piloted and disseminated to healthcare professionals (HCPs) working in palliative care on the island of Ireland (Republic of Ireland and Northern Ireland).

Results: Important factors that motivated HCPs to participate in e-learning are: dedicated time; quick technical and administrative support; computer training before completing an e-learning course; and regular contact with the tutor in online course work. Some $50 \%$ indicated face-to face assistance and hands-on training sessions as the type of e-learning support that they would like to receive.

Conclusion Healthcare professionals' prior experiences and attitudes towards e-learning will guide educators developing programmes. This study indicates the prerequisite for organisational supports and practical considerations to facilitate e-learning uptake.

\section{Key words}

E-learning

Online learning

Palliative care education

Technology-enhanced learning 


\section{Key points}

- Uptake of e-learning is dependent on many factors, including a) compatibility with the topic, b) relevancy to their practice, c) continuing professional development (CPD) requirements, d) course design and pedagogical consideration, e) organisational aspects e.g. designated time to participate in e-learning

- Organisations must be cognisant of employees engaged in e-learning. These include, but are not limited to, providing designated time to engage in learning activities, whether face-to-face or online, adequate IT facilities and software to facilitate seamless access to the online learning environment, dedicated assistance with technical difficulties, regular contact with the tutor, and, for some learners, a dedicated learning space away from the clinical environment.

- This study highlights HCPs' attitudes towards e-learning as a mode of learning for continuing professional development in palliative care education. While participants felt that e-learning was easy to use and had the potential to be useful to them for CPD, more than half of respondents indicated their preference for faceto-face interaction would be a challenge to learning online.

- Educators and instructional designers have a role in developing, designing, supporting and facilitating educational activities crucial to good quality e-learning initiatives.

\section{CPD reflective questions}

- Consider a time you recently accessed or participated in an e-learning programme/ module or activity for your own professional development, what (if any) where the main difficulties or challenges you encountered?

- In future, can you think of ways these challenges could be overcome?

- There are many different types of e-learning activities and programmes. For some of them you work on your own and for others, you connect online at the same time (e.g. zoom, instant chat). In your experience, what aspects of e-learning do you most enjoy / dislike?

- What keeps you motivated when learning online?

\section{Introduction}

Palliative care is a holistic approach to caring for the patient with life-limiting illness and seeks to meet the physical, spiritual, and psychosocial needs of both the patient and their family. The palliative care approach should be a core skill of every clinician, as many patients will have their care needs met without referral to specialist palliative care units or personnel (Health Service Executive (HSE), 2017). According to an Irish Department of Health and Children (DoHC) report: 'Education is a core component of specialist palliative care. The culture of continuing professional education and development should be promoted among health care professionals in all disciplines that are involved in the delivery of palliative care (DoHC, 2001:15).' Integrating the palliative care approach into practice for those with lifelimiting illnesses in different settings requires a workforce that has the competencies to deliver this care. 
Competency consists of core abilities required to fulfil one's role (Fukada, 2018) and represent a combination of knowledge, understanding, skills and abilities (Ryan et al, 2014). The palliative care competency framework (HSE, 2014) recommends six core domains of competence that all healthcare professionals (HCPs) should possess, regardless of their role or the level of palliative care provided. The European Association for Palliative Care (EAPC) paper (Gamondi et al, 2013) on core competencies in palliative care education supports the use of shared learning opportunities across countries and that there is evidence that using digital learning tools enhances understanding of palliative care theory and its application to practice'

E-learning includes any means of delivering learning by the internet (Whittington, 2000). Digital media has the potential to appeal to individuals with different learning styles and preferences for different modes of learning (Fleming and Baume, 2006). E-learning consists of a variety of instructional activities used in a diverse ways. It can encompass asynchronous real-time activity such as live webinar, video conferencing, simulated learning or online collaborative discussions, which are often facilitated or guided by a subject expert such as a tutor or mentor. Other e-learning activities can be accessed in the student's own time and pace.

The advantages and disadvantages of e-learning have been well documented (Gharibpinah and Zamani, 2011; Al-Shorbaji et al, 2015; Arkorful and Abaidoo, 2015; Sinclair et al, 2016; Daniels and Downing, 2018). E-learning allows flexibility for HCPs to update their clinical knowledge and skills, permitting self-paced learning to occur at a time that suits the learner. From an organisational perspective, online learning platforms record employee training, a learner's progress and completion of assessments. E-learning requires motivation and may not suit all learning styles.

The evidence suggests that there may be no difference between e-learning and traditional learning in acquisition of knowledge and user satisfaction (Lahti et al, 2014; Sinclair et al, 2016), although variations in the instructional activities in both e-learning and traditional programmes make them difficult to compare (Al-Shorbaji et al, 2015). E-learning has the capacity to meet the challenge of providing palliative care education to all HCPs to ensure multidisciplinary teams (MDTs) in hospitals, nursing homes, the community and specialist palliative care centres have the necessary competencies to provide the appropriate level of palliative care to patients and their families.

In 2007, the Irish health service launched its online platform 'HSELand.ie', delivering elearning to HCPs. Similarly, Irish hospices started to explore e-learning as a mode of delivering palliative care education and the All-Ireland Institute of Hospice and Palliative Care (AllHPC) established a learning hub to host e-learning programmes in palliative care (https://aiihpc.org/). Despite increased popularity, it has not been readily integrated into nurse education (Petit dit Dariel et al, 2013).

There may be differences between the field of study and interest in e-learning programmes (Lakbala, 2016), or there may be content-related limitations on e-learning uptake (Lahti et al, 2014). Adoption of e-learning is dependent on a variety of factors relating to the technology, pedagogy and context, as well as intrinsic factors relating to the individual themselves (AlShorbaji et al, 2015).

The technology acceptance model is a widely used model to understand acceptance of technology (Davis et al, 1989), whereby actual use is influenced by intention to use and is dependent on attitudes towards technology. Other factors affecting attitudes include 
perceived ease of use, usefulness of the technology, subjective norm and self-efficacy. Despite the rise in e-learning by academic institutions and healthcare organisations, there is no study examining healthcare professionals' attitudes towards e-learning as a method of delivering palliative care education.

This study had two aims: 1) To understand the barriers that exist for healthcare professionals accessing e-learning courses in palliative care and 2) to examine how we can facilitate the adoption of e-learning by those undertaking e-learning courses.

\section{Method}

\section{Data collection procedure}

The study is a mixed method study consisting of two phases. In Phase 1, data was collected from a convenience sample of doctors, nurses, allied HCPs and healthcare assistants using a questionnaire instrument. Respondents were employed in specialist palliative care in hospices, specialist palliative day care services and the community on the island of Ireland (Republic of Ireland and Northern Ireland).

\section{Instrument}

\section{Questionnaire}

A literature search was undertaken to ascertain if a valid and reliable instrument could be used or adapted for this study. We did not find a validated tool that could be adapted to HCPs in this setting. We designed and developed an instrument based on a comprehensive review of the literature. Multiple scale items were primarily adapted from a previous scale (Watkins et al, 2004) and used to elicit self-efficacy in relation to computer skills and engaging online, perceived usefulness and ease of use with respect to e-learning, normative beliefs and their motivation to learn in an online environment.

The four-page questionnaire is comprised of 25 questions covering 1) Demographics, 2) Access to computers and the internet, 3) Confidence using IT and e-learning, 4) Prior experience of e-learning, 5) Attitudes towards e-learning - Barriers and facilitators in palliative care education

\section{Piloting}

The survey instrument was pre-tested for content validity with six experts in the subject areas of palliative care, information and communications technology (ICT) and education. Based on their feedback, this instrument was subsequently revised and re-drafted. The instrument was piloted with $10 \mathrm{HCPs}$ to clarify their understanding of the items used in the instrument, ease of use, length of questionnaire and the time taken to complete.

Subsequent revisions to the instrument were carried out based on feedback received in the pilot phase and mainly concerned the length of the questionnaire and re-wording some of the statements for clarity.

\section{Access and ethical approval}

An email explaining the purpose of the study was sent to the chief executive officer and the director of nursing in each of the 13 hospice services in Ireland and permission was requested to conduct the study in each organisation. Ethical approval was then sought and 
obtained from eight Research Ethics Committees in the Republic of Ireland and Northern Ireland for both phases of the study.

Respondents were informed that their anonymity would be upheld in the reporting of the data and that it would be stored securely to ensure confidentiality. The transcriber was also asked to sign a confidentiality agreement.

\section{Sampling procedure: questionnaires}

Print and online questionnaires were sent to a key individual (gatekeeper) in each of the hospice services in the Republic of Ireland and Northern Ireland, inviting clinical staff from specialist palliative inpatient units, homecare and day care services to participate in the study. A reminder email was sent to each organisation approximately 3 weeks later. Respondents had the option of entering a prize-draw, which was used as an incentive to complete the questionnaire. Information with the questionnaire explained the purpose of the study, that participation was voluntary and that all data would be kept secure and anonymous.

\section{Findings}

\section{Respondent profile}

There were 397 responses obtained from a convenience sample sent to 13 specialist palliative care centres that had inpatient units located in the Republic of Ireland and in Northern Ireland, as well as all specialist palliative care homecare services located in the Republic of Ireland.

It was not possible to obtain an accurate response rate across all sites. The average response rate obtained across six sites was approximately 35\%. The demographic characteristics of the participants are given in Table 1.

Some $82 \%$ of respondents used a computer at least once a week or more at work. Similarly, most (92\%) reported using computers outside of work at least once a week. Most had internet access both in work (92\%) and outside of working hours (97\%). Despite the high rate of internet access among participants, only $50 \%$ of questionnaires were completed online.

\section{Computer self-efficacy}

Some $53 \%$ indicated their level of confidence using computers was good or excellent; $39 \%$ rated themselves as average in terms of their confidence. Only $8 \%$ indicated they had poor or very poor confidence with computers (Table 2).

Confidence carrying out computer tasks was measured between 1 (= Not confident) to 5 (=Very Confident), reported in Table 3 . Some $62 \%$ indicated that they would feel confident using e-learning as a learner, even if they had never used it before, reported in Figure 1.

\section{E-learning experience}

Some $37 \%$ had completed a course previously using e-learning, with $43 \%$ having completed a blended course that had an e-learning component. As part of continuing professional activities, 52\% reported listening to podcasts or watching videos and $50 \%$ reported that they completed quizzes online. Some $46 \%$ of respondents had uploaded assignments to a website for assessment and 39\% reported using learning management systems such as Moodle, 
Blackboard or Sulis. Participation was lowest for live webinars (17\%), blogs (18\%) and video conferences (26\%).

\section{Attitudes towards e-learning}

Respondents considered e-learning as useful for their continuing professional development. Some $63 \%$ believed that e-learning is easy to use, while $62 \%$ indicated that there were limitations with e-learning for palliative care education. Some $57 \%$ reported that positive aspects outweighed negative aspects of using e-learning in palliative care and $55 \%$ reported that their colleagues used e-learning. Overall, their attitude towards e-learning was positive. Results are reported in Figure 1 . Some $80 \%$ reported that if a course or study module they were interested in became available, they were likely or highly likely to avail of it (Table 4). Respondents were asked to indicate which topics were most/least suited to e-learning. Eighty-five percent of respondents indicated that the topic "Principles of Palliative Care" was most suited to e-learning followed by" Professional \& ethical practice in palliative care" (67\%) and "Care planning \& collaborative practice" (58\%). Eighty-one percent indicated that "Communication" was least suited to e-learning followed by "Loss, grief and bereavement" (50\%).

\section{Barriers to e-learning}

Limited time is a barrier to using e-learning for $68 \%$ and $54 \%$ indicated a preference for faceto-face interaction. Nearly one-third felt that remaining motivated would be a challenge in elearning. Lack of computer skills was a barrier to $34 \%$ (Figure 2).

There were 39 responses to the open-ended question about other challenges to e-learning. An analysis of qualitative data from the open-ended question found that approximately onethird highlighted the importance of face-to-face interaction.

The responses included:

'Lack of opportunity for impromptu engagement/group dialogue'

'I think palliative care education is enhanced by personal and group interaction'

'Unable to ask questions as you go'

Some $23 \%$ reported that access to good IT facilities is particularly important in the workplace, especially a designated space without interruptions. In the open-ended responses, the next challenge is having designated time to carry out e-learning, with one respondent stating that there is a 'Risk of limited study leave/support from work organisation, as the time spent on e-learning is hidden' (18\%).

Other challenges when participating in e-learning are dependent on the course design, such as having deadlines to keep people motivated, blended learning, well-designed courses with embedded links that are functional. Course outlines should indicate appropriate target audience and course content, it was felt. Lack of confidence and computer skills were also noted by $10 \%$ of responses to this question eg. "I think this is an "age thing", as most of the younger nurses were brought up with modern technology and more natural for them'.

Respondents were asked what would prevent them from participating in a course with an elearning component. There were 244 responses to this open-ended question (61.5\%). The responses were analysed and coded and 10 main factors were identified. Time constraints during already busy working schedules was the main inhibitor to studying online (42\%). 
'Would depend on the time required to complete it versus how busy my clinical post was at that time. Being said, e-learning courses would take up much less time than classroom based course: travelling to and from etc, and could be done to own schedule'

Course design also plays a role. 'E-learning is not a filing cabinet for information - it needs to be a very interactive and a sharing of ideas with those in your personal field'. Course issueswhich included preference for blended learning, too much course content, poor quality of course, suitability of topic, lack of discussion-are other factors that would prevent respondents from doing a course with an e-learning component.

Approximately $27 \%$ cited lack of computer skills, lack of confidence and a requirement for technical or other support as factors preventing them doing e-learning. Participants described a preference for face-to-face learning (8\%), cost/finance (6\%), motivation/self-discipline (5\%), relevancy (3\%), accessibility to computer resources, including software, computers and good quality internet connection (6\%).

\section{Motivators to use e-learning}

\section{What would motivate you to use e-learning in future?}

Dedicated time to participate in e-learning activities was indicated as either quite important or a very important motivating factor by $89 \%$ of respondents followed by quick technical and administrative support you could call on (87\%) as reported in Figure 3 . Sixty-five percent indicated that regular contact with the tutor would be quite or very important to the success on online course work. Face to face assistance $(50 \%)$ and hands-on training (50\%) were indicated as the most preferred type of support with e-learning by respondents $(n=378)$, followed by online assistance $(47 \%)$, telephone $(33 \%)$, booklet ( $28 \%$ and video demo (25\%).

There was a $65.5 \%$ response rate (260/397) to this open-ended question. When the data was coded, $28 \%$ cited accessibility and flexibility as a motivator to engage with online learning, in terms of doing it from anywhere, in your own time and pace.

Approximately one in five stated that keeping up to date for their personal and professional development would be a motivator to do an e-learning course. There was an emphasis on courses that were accredited, to enable practitioners to 'update palliative skills and knowledge' and in 'meeting the criteria for professional CPD'. Some $20 \%$ stated courses or topics that were relevant and interesting would motivate them to participate in e-learning. Nearly $14 \%$ stated that 'dedicated time to participate in e learning within working hours' would be an important factor.

Some $4 \%$ cited better access to computers/faster internet at home and work without distractions, while $7 \%$ cited various supports, including education and training and practical instruction using computers and how to access e-learning. Some $8.5 \%$ cited ease of use, followed by improving their computer skills, having prior experience of e-learning and if was recommended by other colleagues.

'Given time within my working day to access a computer in a quiet room with no distraction'

'If I was really interested in the course-came highly recommended.'

'It is the future. Most onsite training is on the East coast. I live in the West Coast - this usually involves up to a 6-hour round trip in a day!' 
'Ease of use, the chance to repeat if necessary, my time and my pace'

'Relevant to my education needs. Accreditation with a recognised body'

\section{Discussion}

Time is the main barrier to using e-learning for HCPs (Franz et al, 2015). Although not a dominant factor, computer skills were a challenge to using e-learning for one-third of participants. An evaluation of a distance learning programme in palliative care used a virtual learning environment to support learners and found that candidates' confidence in their IT skills increased after doing the distance learning programme (Callinan and McLoughlin, 2012).

Two-thirds of respondents perceived e-learning as easy to use and were willing to undertake e-learning if a course they were interested in became available. Perceived usefulness of elearning was also high (86\%). While participants felt that e-learning was easy to use and had the potential to be useful to them for CPD, more than half of respondents preferred face-toface interaction in palliative care education.

This study reported that HCPs require technical and administrative support when completing e-learning programmes. Similar to Lakbala (2016), we found that limited communication and engagement with the course instructor during the course and lack of guidance, information and training on e-learning prior to course commencement were also barriers to successfully using e-learning. Preparing learners for e-learning has been highlighted in other studies as a factor for successful e-learning adoption (Watkins et al, 2004). Face-to-face assistance is a most valuable type of support with e-learning. Support should be provided in multiple formats, such as online, telephone contact, leaflets and video demonstration.

Almost two-thirds of respondents reported that e-learning had limitations in palliative care education, citing 'limited interaction'. Other studies have highlighted learner preference for greater face-to-face interaction in palliative care education, especially the desire for practical experience with patients (De Vliegher et al, 2015; Selman et al, 2017; Schulz-Quach et al, 2018). Mentoring and the opportunity to discuss ideas with colleagues or experts in the field have been found to be highly valued by HCPs (De Vliegher et al, 2015). According to Cook et al (2010), practice exercises, interactivity, repetition and feedback also improved learning outcomes. Ongoing promotion of e-learning is necessary to ensure that knowledge is retained (Rawlings et al, 2020). Criteria for the success of an e-learning module were user-friendliness, a thorough explanation about the use of the platform (63.7\%), a thorough development of the subject, the possibility to exchange ideas with colleagues or teachers, and the availability of online illustrations (De Vliegher et al, 2015).

The palliative care competency framework recommends that all HCPs should be competent in six core domains. Teaching some elements of these domains may be suited to experiential learning and e-learning may meet the challenge by supplementing some aspects of classroom teaching, as is the case already. Experiential and peer learning are an important mode of learning about palliative care and end-of-life care (Selman et al, 2017). The ECHO telementoring model connects multidisciplinary teams of palliative care specialists with HCPs in other settings and incorporates didactic teaching, followed by shared reflective learning and discussion from real-life scenarios (White et al, 2016; De Witt Jansen et al, 2018). This model values learning from the shared community of practice (Lave and Wenger, 1991). Telelearning facilitated by palliative care experts with elements of mentoring and peer support may provide sustainable education in resource-limited settings, contributing to greater understanding of the palliative care approach, leading to integration into clinical practice. Our 
study found that HCPs had a positive attitude to e-learning and perceived it as easy to use. The 'flipped classroom' is a blended approach that facilitates classroom time for more discussion and reflection (Roehl et al, 2013).

Participants felt that e-learning would not meet their learning needs for topics such as communication at end of life or bereavement. Empathic communication skills are core elements of the discipline. In another study, there were no differences in knowledge between e-learners and non-e-learners in undergraduate medical students, but the e-learning module in palliative care did not increase their self-estimation of competence in communicating with dying patients and their relatives (Schulz-Quach et al, 2018).

Palliative and end-of-life care requires more innovative teaching methods than formal didactic lessons (Selman et al, 2017) and a clear understanding of adult learner needs in different contexts should be explored (Squires, 2018). Understanding attitudes, knowledge and experiences of using e-learning in palliative care education will enhance understanding the barriers that exist in adopting e-learning among learners in Ireland.

\section{Limitations}

While this study included HCPs from across the island of Ireland, there are a number of limitations. First, it was limited to those employed in specialist palliative care. This topic is highly emotive and may be perceived as not particularly suited to e-learning. Teaching holistic care at end of life seeks to promote greater empathy and compassion and therefore this subgroup may regard e-learning in palliative care education differently than those working in another speciality.

Another limitation is that it is likely that there may be cultural differences between organisations in the extent to which e-learning is used by staff. Some hospices and organisations had their own education departments or were palliative care education providers. Some organisations used e-learning platforms such as Moodle and had dedicated e-learning/educational technology personnel. This study was conducted prior to the Covid-19 pandemic and perceptions on e-learning may have changed since.

The questionnaire was not validated. However, the instrument was pre-tested for content validity and piloted with 10 HCPs. The outcome measures are self-reported and reflect HCPs' perceptions only.

\section{Conclusions}

Future studies should consider which methods and elements of instructional design and pedagogy impact on learning outcomes and behavioural change and under what circumstances (Lahti et al, 2014; Taroco et al, 2017). The most important facilitators ranked in order of importance were:

1) Dedicated time to participate in e-learning activities

2) Quick technical and administrative support

3) Dedicated computer training before completing an e-learning course

4) Regular contact with the tutor in online course work

Incorporating, blending and embedding digital technology and e-learning into palliative care education offers limitless possibilities and an alternative mode of learning. Educators and instructional designers must consider pedagogy when developing programmes. Future 
studies should examine how technology could be used to effectively enhance learning and in what instances it is found to be either a hindrance to or an enabler of learning.

Acknowledgements: The author wishes to thank the All Ireland Institute of Hospice and Palliative Care for funding this study as part of a research fellowship and to Dr. Oliver McGarr, University of Limerick for supervising it. Thanks to the study sites and those who participated in this research.

Conflict of Interest: In her work role, the author also develops e-learning programmes.

\section{References}

Al-Shorbaji N, Atun R, Car J, Majeed A, Wheeler E. (ed.) ELearning for undergraduate health professional education. A systematic review informing a radical transformation of health workforce development. Geneva: World Health Organisation; 2015. https://www.who.int/hrh/documents/elearning_hwf/en (accessed 26 February 2020)

Arkorful V, Abaidoo N. The role of e-learning, advantages and disadvantages of its adoption in higher education. Intern J Instruct Techn and Distanc Learn. 2015; 12(1): 29-42. http://itdl.org/Journal/Jan_15/Jan15.pdf\#page=33 (accessed 25 February 2020)

Callinan J, McLoughlin K. Evaluation of a virtual learning environment (VLE) to support the delivery of the European Certificate in Essential Palliative Care. Limerick: Milford Care Centre; 2012.

Cook D, Levinson A, Garside S. Instructional design variations in internet-based learning for health profession education: a systematic review and meta-analysis. Acad Med. 2010; 85(5): 909-922. https://doi.org/10.1097/ACM.0b013e3181d6c319

Daniels A, Downing J. Increasing access to children's palliative care for education through elearning; a review of the ICPCN experience. Int J Palliat Nurs. 2018; 24(7):351-358. https://doi.org/10.12968/ijpn.2018.24.7.351

Davis FD, Bagozzi RP, Warshaw PR. User acceptance of computer technology: A comparison of two theoretical models. Manage Sci. 1989; 35(8):982-1003. https://doi.org/10.1287/mnsc.35.8.982

De Vliegher K, Paquay L, Cordyn S, Heirstrate L, Goense E, Pechon S, Labalue, J, Putzeys D. Home Nurses' Opinions Toward e-Learning in Continuing Education. Home Health Care Manage \& Pract. 2015; 27(4):216-223. https://doi.org/10.1177/1084822315573933

De Witt Jansen B, Brazil K, Passmore P, Buchanan H, Maxwell D, Mcilfatrick SJ, Morgan SM, Watson $\mathrm{M}$, Parsons $\mathrm{C}$. Evaluation of the impact of telementoring using $\mathrm{ECHO}[\mathrm{c}]$ technology on healthcare professionals' knowledge and self-efficacy in assessing and managing pain for people with advanced dementia nearing the end of life (Report). BMC Health Serv Res. 2018; 18(1). https://doi.org/10.1186/s12913-018-3032-y 
Department of Health and Children. Report of the National Advisory Committee on Palliative Care. Dublin: Department of Health and Children; 2001.

https://www.lenus.ie/handle/10147/42522 (accessed 24 February 2020)

Fleming N, Baume D. Learning Styles Again: VARKing up the right tree!, Educational Developments, SEDA; 2006. https://semcme.org/wp-content/uploads/Flora-EducationalDevelopments.pdf (accessed 24 February 2020)

Franz S, Behrends M, Haack C, Marschollek M. Benefits and Barriers of E-Learning for Staff Training in a Medical University. Stud Health Technol Inform. 2015; 213:99-102.

Fukada M. Nursing competency: definition, structure and development. Yonago Acta Med. 2018; 61 (1):1-7. http://doi.org/10.33160/yam.2018.03.001

Gamondi C, Larkin P, Payne S. Core competencies in palliative care: an EAPC White Paper on palliative care education - part 2. Eur J Palliat Care. 2013; 20(3):140-145. https://www.lenus.ie/handle/10147/325630 (accessed 25 February 2020)

Gharibpinah M, Zamani A. Assessing advantages and disadvantages of e-learning. J Am Sci. 2011; 7(4):519-524.

Health Service Executive. Palliative Care Services - Three Year Development Framework (2017-2019). Dublin: HSE; 2017. https://www.hse.ie/eng/services/publications/clinicalstrategy-and-programmes/palliative-care-services-development-framework.pdf (accessed 24 February 2020)

Lahti M, Hätönen $\mathrm{H}$, Välimäki M. Impact of e-learning on nurses' and student nurses knowledge, skills, and satisfaction: a systematic review and meta-analysis. Int J Nurs Stud. 2014; 51:136-149. http://doi.org/10.1016/j.ijnurstu.2012.12.017

Lakbala P. Barriers in Implementing E-Learning in Hormozgan University of Medical Sciences. Glob J Health Sci. 2016; 8(7):83-92. http://doi.org/10.5539/gjhs.v8n7p83

Lave J, Wenger E. Situated Learning: Legitimate Peripheral Participation. Cambridge: Cambridge University Press; 1991.

Petit dit Dariel O, Wharrad $\mathrm{H}$, Windle R. Exploring the underlying factors influencing elearning adoption in nurse education. J Adv Nurs. 2013; 69(6):1289-300. http://doi.org/10.1111/j.1365-2648.2012.06120.x

Rawlings D, Tiernan J, Moores C. E-Learning: who uses it and what difference does it make? Int J Pall Nurs. 2020; 25(10: 432-442. https://doi.org/10.12968/ijpn.2019.25.10.482

Roehl A, Reddy SL, Shannon GJ. The flipped classroom: An opportunity to engage millennial students through active learning strategies. J Fam Cons Sci. 2013; 105(2):44-49.

Ryan K, Connolly M, Charnley K, Ainscough A, Crinion J, Hayden C, Keegan O, Larkin P, Lynch M, McEvoy D, McQuillan R, O'Donoghue L, O'Hanlon M, Reaper-Reynolds S, Regan J, Rowe D, Wynne M. Palliative Care Competence Framework Steering Group. Palliative Care Competence Framework. Dublin: Health Service Executive; 2014. https://www.lenus.ie/bitstream/handle/10147/322310/CompetenceFrameworkFinalVer sion.pdf?sequence=1 (accessed 28 February 2020)

Schulz-Quach C, Wenzel-Meyburg U, Fetz K. Can elearning be used to teach palliative care? - medical students' acceptance, knowledge, and self-estimation of competence in 
palliative care after elearning. BMC Med Educat. 2018; 18:82.

http://doi.org/10.1186/s12909-018-1186-2

Selman LE, Brighton L, Robinson V, George R, Khan SA, Burman R, Koffman J. Primary care physicians' educational needs and learning preferences in end of life care: A focus group study in the UK. BMC Palliat Care BMC series. 2017; 16:17.

http://doi.org/10.1186/s12904-017-0191-2

Sinclair PM, Kable A, Levett-Jones T, Booth D. The effectiveness of internet-based e-learning on clinician behaviour and patient outcomes; a systematic review. Int J Nurs Stud. 2016; 57:70-81. doi:10.1016/j.ijnurstu.2016.01.011

Squires $\mathrm{V}$. Using the $3 \mathrm{E}$ framework in promoting adult learners' success in online environments. Alberta J Educat Res. 2018; 64(2):126-140.

https://journalhosting.ucalgary.ca/index.php/ajer/article/view/56381 (accessed 28 February 2020)

Taroco ALC, Valente TCO \& Carboquim CS. Distance learning for updating health professionals in palliative care: a systematic review. BMJ Supp \& Palliat Care. 2017; 7(2):205-211. http://doi.org/10.1136/bmjspcare-2015-001042

Watkins R, Leigh D, Triner D. Assessing readiness for e-learning. Perform Improv Quart. 2004; 17(4): 66-79. https://doi.org/10.1111/j.1937-8327.2004.tb00321.x

White C, Mcllfatrick S, Dunwoody L, Watson M. F09-C Supporting and Improving Community Health Services - A Prospective Evaluation of ECHO Technology in Community Palliative Care Nursing Teams. J Pain Symp Manag. 2016; 52(6):e51-e52. http://doi.org/10.1016/j.jpainsymman.2016.10.062

Whittington D. Evaluating three years' use of virtual university. Qual Assur Educat. 2000; 8(1):48-53. https://doi.org/10.1108/09684880010313153 


\section{Tables and figures}

\section{Figure 1. Attitudes towards e-learning}

\section{Attitudes towards E-Learning}

I think that I would be able to complete an E-Learning course even if there were distractions (Online, television

My colleagues use E-Learning

Positive aspects outweigh negative aspects of using ELearning in palliative care

I believe there are limitations with E-Learning for learning about palliative care

I believe E-Learning is easy to use

I believe E-Learning is useful for my continuing professional development

I would feel confident using E-Learning as a learner even if I had never used it before

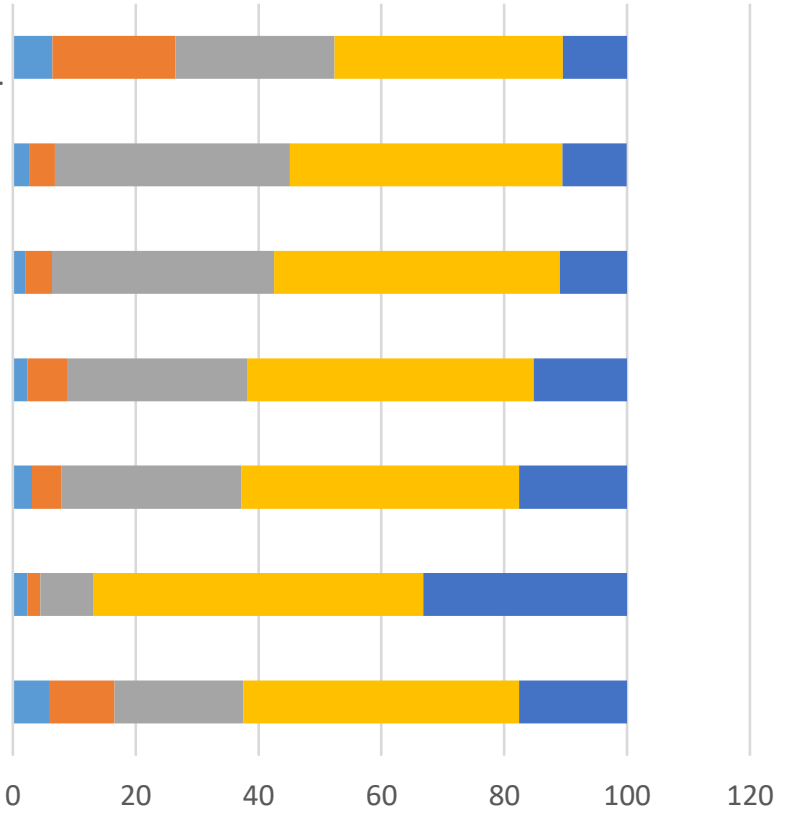

Strongly Disagree $\square$ Disagree $\square$ Not sure $\square$ Agree $\square$ Strongly Agree 
Figure 2. Factors challenging healthcare professionals using e-learning

As a learner, what would be your main challenges with E-Learning?

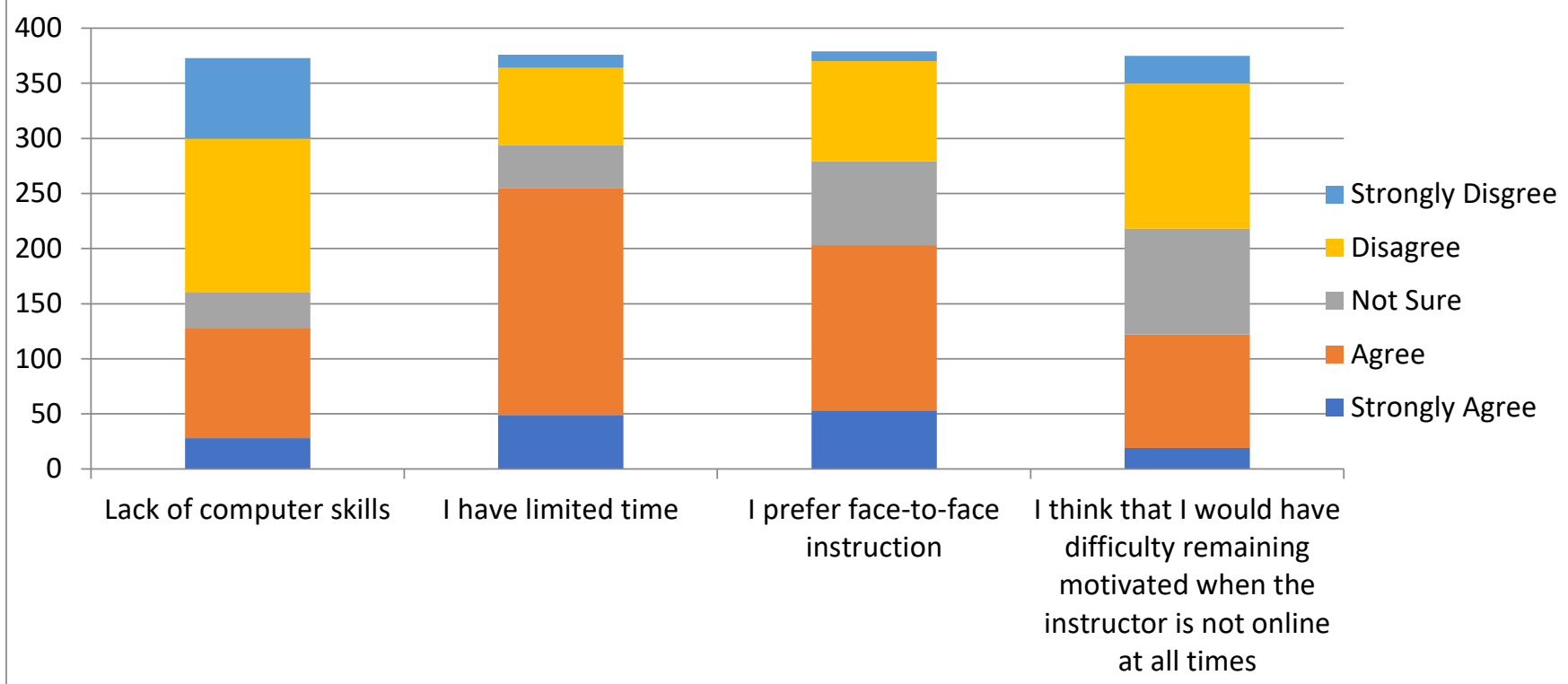


Figure 3. Factors motivating healthcare professionals to use e-learning

As a learner, which of the following are likely to motivate you to use e-learning in future?

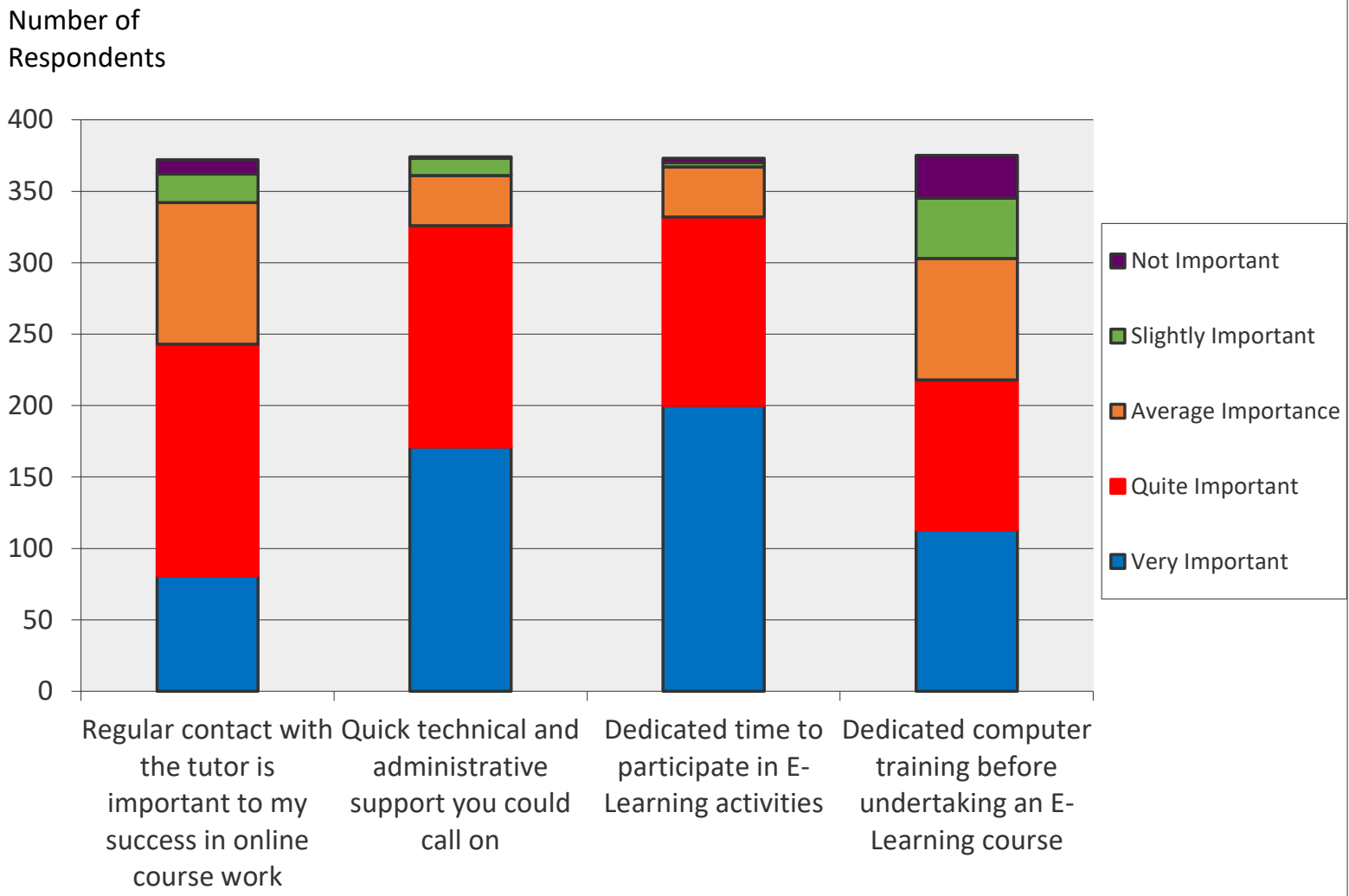

Table 1. Participant demographics

\begin{tabular}{|c|c|c|}
\hline Participant's profile & & $\%$ \\
\hline \multirow[t]{2}{*}{ Gender } & Female & $90.8 \%$ \\
\hline & Male & $9.2 \%$ \\
\hline \multirow[t]{5}{*}{ Age (years) } & $16-24$ & $1.6 \%$ \\
\hline & $25-34$ & $17.4 \%$ \\
\hline & $35-44$ & $31.1 \%$ \\
\hline & $45-54$ & $33.0 \%$ \\
\hline & $55+$ & $16.9 \%$ \\
\hline \multirow[t]{7}{*}{ Professional group } & Nurse & $64.6 \%$ \\
\hline & Doctor & $10.5 \%$ \\
\hline & Occupational therapist & $2.7 \%$ \\
\hline & Dietician & $0.5 \%$ \\
\hline & Social worker & $5.9 \%$ \\
\hline & Physiotherapist & $4.3 \%$ \\
\hline & Chaplain & $1.3 \%$ \\
\hline
\end{tabular}




\begin{tabular}{|l|l|l|}
\hline & Pharmacist & $1.3 \%$ \\
\hline & Speech and language therapist & $0.0 \%$ \\
\hline & Healthcare assistant & $13.1 \%$ \\
\hline Setting & Hospice-specialist palliative inpatient unit & $60.1 \%$ \\
\hline & Community-based specialist palliative care & $32.5 \%$ \\
\hline & Specialist palliative day care & $7.5 \%$ \\
\hline & Other & $3.8 \%$ \\
\hline Jurisdiction & Republic of Ireland & $68 \%$ \\
\hline & Northern Ireland & $32 \%$ \\
\hline
\end{tabular}

Table 2. Confidence using computers

\begin{tabular}{|l|l|l|l|l|l|l|l|}
\hline Confidence & Very Poor & Poor & Average & Good & Excellent & $\begin{array}{l}\text { Rating } \\
\text { average }\end{array}$ & $\begin{array}{l}\text { Response } \\
\text { count }\end{array}$ \\
\hline $\begin{array}{l}\text { Confidence using } \\
\text { computers }\end{array}$ & $3(0.8 \%)$ & $26(7 \%)$ & $146(39.4 \%)$ & $144(38.7 \%)$ & $53(14.2 \%)$ & 3.59 & 372 \\
\hline Skipped question & & & & 25 \\
\hline
\end{tabular}

Table 3. Confidence with IT activities

Confidence doing the following IT activities

a ) I have basic skills to operate a computer (logging on, saving files, creating folders)

b) Searching the internet and connecting to the website I want

c) I can send an email with a file attached

d) I think that I would be comfortable using a computer several times a week to participate in a course

e) I think that I would be comfortable communicating effectively with others using email, online forums or chat

f) I think that I would be comfortable engaging in an elearning course

g) Using Microsoft Word

h) Internet shopping

\begin{tabular}{|l|l|l|l|l|}
\hline Very poor & Poor & Average & Good & Excellent \\
\hline 12 & 28 & 90 & 122 & 135 \\
\hline 4 & 7 & 53 & 152 & 168 \\
\hline 16 & 22 & 57 & 115 & 169 \\
\hline 23 & 23 & 83 & 131 & 135 \\
\hline 20 & 29 & 95 & 143 & 96 \\
\hline 23 & 26 & 72 & 150 & 116 \\
\hline 23 & 27 & 70 & 141 & 125 \\
\hline
\end{tabular}

Table 4. Likelihood of availing of a course with an e-learning component in future

If a course or study module you were interested in became available, what is the likelihood of you availing of it, if it had an e-learning component?

\begin{tabular}{|l|l|}
\hline Response & $\mathbf{n}(\mathbf{\%})$ \\
\hline Highly unlikely & $16(4.2 \%)$ \\
\hline Unlikely & $11(2.9 \%)$ \\
\hline Not sure & $48(12.7 \%)$ \\
\hline Likely & $201(53.3 \%)$ \\
\hline Highly likely & $101(26.8 \%)$ \\
\hline Rating average & 3.95 \\
\hline
\end{tabular}


